\title{
Modal Analysis of High-pile Wharf Structure Based on Fluid-Solid Coupling
}

\author{
Wang Hong, Feng Sen, Guo Zhichao
}

\begin{abstract}
Taking a high-pile wharf as an example, this paper uses ANSYS finite element software to establish a three-dimensional finite element simulation model of the wharf, and conducts a preliminary modal analysis to study the vibration characteristics of the high-pile wharf structure, providing structural design fault diagnosis and theoretical basis. Through the analysis of the natural frequency of the high-pile wharf model structure under waterless conditions and under water conditions, the influence of water body on the vibration frequency of the wharf is further explored.
\end{abstract}

Index Terms - High-pile wharf; modal analysis; vibration effects; natural frequency

\section{INTRODUCTION}

The high-pile wharf has gradually become the main structural form of domestic and foreign ports. It has a light structure, small wave reflection capability, can withstand large loads, and is suitable for soft soil foundation. It gradually begins to expand into large-scale and deep-water ${ }^{[1]}$. It is very meaningful to study the response of the wharf under different dynamic loads. However, the response of the structure to different dynamic loads is determined by the vibration characteristics of the structure itself. Therefore, the structural modal analysis must be performed before other analysis. Zhou Shiliang ${ }^{[2]}$ used the software to establish the wharf structure model, and made modal analysis on the wharf, then extracted the key modes, analyzed the characteristics of the structure shape, and finally evaluated the safety of the pier structure according to the actual working conditions. Xu Weijun ${ }^{[3]}$ calculated and analyzed the first-order modal frequency increase value of the wharf under different treatment measures by using the three-dimensional finite element program ANSYS for the vibration phenomenon of the wharf structure during operation. In this paper, the influence of fluid on the modal structure of the wharf is considered. The modal analysis of the wharf structure based on fluid-solid coupling is carried out. The modal frequencies and mode characteristics of the wharf structure are analyzed, and the influence of the water body on the modal frequency of the wharf structure is studied.

\section{THE BASIC THEORY OF STRUCTURAL MODAL ANALYSIS}

1. Basic assumptions of modal analysis ${ }^{[4]}$

The modal analysis theory has the following four basic assumptions:

(1)Linear hypothesis: Linear hypothesis means that the dynamic characteristics of the structure are linear, that is, the output caused by any input combination is equal to the output

Wang Hong, Feng Sen, Guo Zhichao, Jiangsu University of Science and Technology, Zhenjiang 212003, China combination, and a set of linear second-order differential equations can be selected to represent its dynamic characteristics. It is important to note that for plastic and contact elements, even nonlinear properties are defined and ignored.

(2)Time invariance hypothesis: The time invariance hypothesis means that the dynamic characteristics of the structure do not change with time, so the coefficients of the equation are constants that are not related to time.

(3)Observability hypothesis: The observability hypothesis means that all the data involved in the dynamic characteristics of the system we are concerned with can be measured.

(4) Obey the Maxwell reciprocity theorem: Obeying the Maxwell reciprocity theorem means that the input of $j$ point at the point of structure $i$ causes the same input at point $j$ to cause the $\mathrm{i}$ point response to be equal. This assumption makes the structure mass, stiffness, damping matrix, and frequency response function all become symmetric matrices.

2 . Basic theory of modal analysis ${ }^{[5 \sim 6]}$

Modal analysis is fundamentally solving a vector of equations with a finite number of degrees of freedom that are undamped and have no external loads. The equation of motion for solving the system is:

$[M]\left\{\boldsymbol{g}+[C]\left\{\boldsymbol{U}^{\mathbf{g}}+[K]\{U\}=\{F(t)\}(1)\right.\right.$

Where: $[M]$ represents the structural mass matrix, $[C]$ represents the structural damping matrix, $[K]$ represents the structural stiffness matrix, $\{$ represents the node acceleration vector, $\{\boldsymbol{E}\}$ represents the node velocity vector, $\{U\}$ represents the node displacement vector, $\{F(t)\}$ represents the load function as a function of time.

When there is no dynamic load, the vibration that the structure is free to generate is called structural self-vibration. Because the effect of damping on structural modal parameters is very small and negligible, the expression of the natural vibration equation without damping is:

$$
[M]\{U \&+[K]\{U\}=0
$$

Assuming that the structural vibration is a simple harmonic motion, that is $\{U\}=|\phi| \sin (\omega t+\varphi)$ Taking

$$
\left\{\boldsymbol{g}=-\omega^{2}|\phi| \sin (\omega t+\varphi) \quad\right. \text { into }
$$

equation (2), the characteristic equation of structural vibration can be obtained as follows:

$$
\left(\left[\left(K^{3}\right]-\omega^{2}[M]\right)|\phi|=\{0\}\right.
$$


Where: $\omega$ is the natural frequency and $|\phi|$ is the natural mode. The modal analysis is mainly to solve the eigenvalue and the corresponding eigenvector $\left|\phi_{i}\right|$ in the characteristic equation. $\omega_{i}$

\section{SECOND, GENERAL SITUATION OF THE WHARF}

1. Analytical model of high-pile wharf

The wharf model selects the dock structure of the $2 \# \sim 5 \#$ berth in a port area. The wharf is a modified model. The original wharf is 30,000 tons. After the renovation, ships with 50,000 to 70,000 tons can be berthed. The detailed modification plan is to first add a pile table at the side of the existing shelf side of the river, and add four diameter steel pipe piles on the river side for each frame structure to be modified, and then combine the upper pouring node with the existing one ${ }^{[7]}$. Form a new row of shelves, the schematic diagram of the modified dock section is shown in Figure 1.

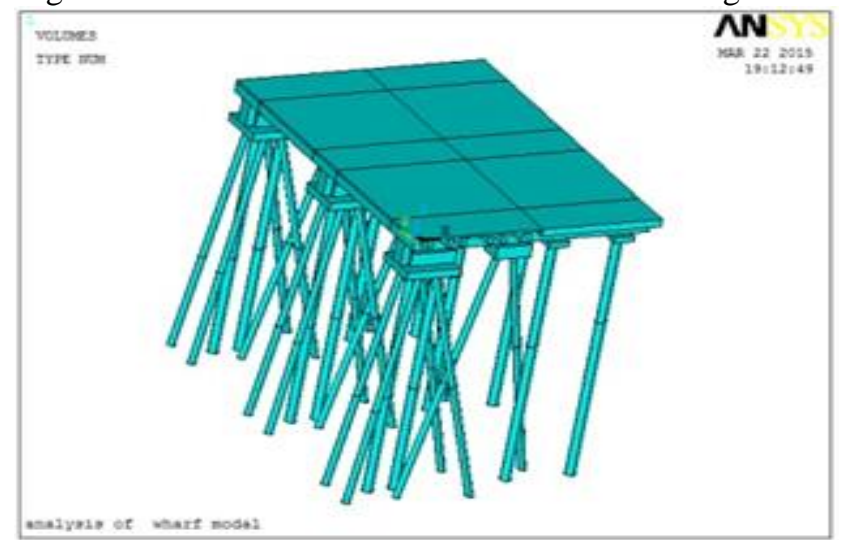

Fig 1 The picture of high-piled wharf after reconstruction

The established wharf structure model includes a front cap and a rear cap, wherein the front cap and the rear capjj include a wharf superstructure and a steel pipe pile, and the steel pipe pile includes a straight pile and a fork pile. Figure 2 is a 2 span 3 truss shelves with a pier structure.

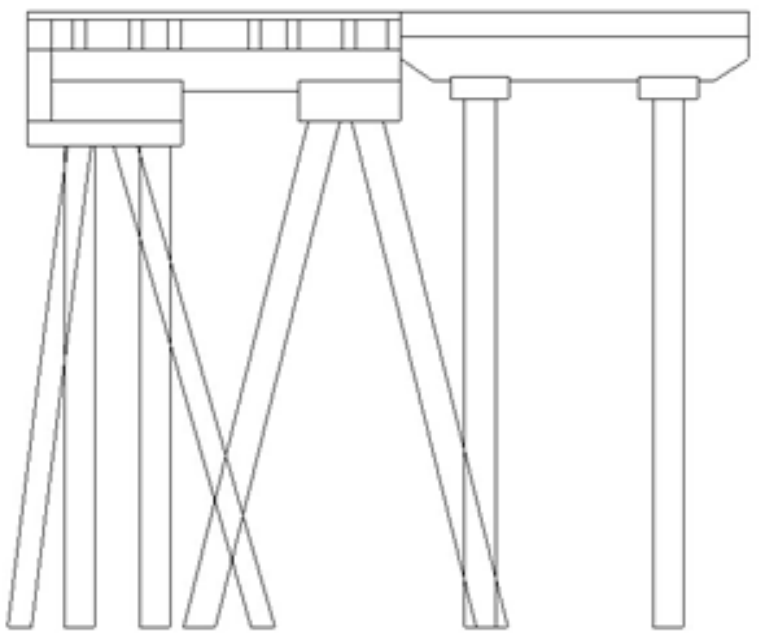

Fig 2 The picture of high-piled wharf model

\section{Selection of model materials}

The high-pile wharf includes the upper structure and the pile, wherein the upper structure is made of concrete material and the pile-based structure is selected from steel pipe piles. The material parameters are shown in Table 1. The gravitational acceleration is $9.8 \mathrm{~m} / \mathrm{s}^{2}$, the water density is $1000 \mathrm{~kg} / \mathrm{m}^{3}$, and sound velocity in water is $1400 \mathrm{~m} / \mathrm{s}$.
Table 1 The parameters of concrete and steel pipe pile

\begin{tabular}{llcc}
\hline Material & $\begin{array}{l}\text { Elastic } \\
\text { Modulus } \\
(\mathrm{Pa})\end{array}$ & $\begin{array}{l}\text { Poisson's } \\
\text { ratio }\end{array}$ & $\begin{array}{l}\text { Density } \\
\left(\mathrm{kg} / \mathrm{m}^{3}\right)\end{array}$ \\
\hline Concrete & $3.0 \times 10^{10}$ & 0.2 & 2700 \\
Steel pipe pile & $2.1 \times 10^{11}$ & 0.3 & 7850 \\
\hline
\end{tabular}

\section{Selection of model unit}

Before establishing the wharf structure model, first assume that the wharf superstructure and the pile foundation structure are uniform and continuous isotropic elastomers, and the model is all simulated using SOLID185 unit. The water is simulated using FLUID30 unit. The unit has eight nodes, and each node has four degrees of freedom. They are the displacement degrees of freedom on $\mathrm{X}, \mathrm{Y}$, and $\mathrm{Z}$ plus a pressure degree of freedom. The unit is isotropic. The material, the density of water and the velocity of sound as input into the finite element program of DENS and SONC, and do not take into account the loss effect caused by the viscosity of the fluid ${ }^{[8]}$. Solve the modality of the wharf structure under waterless and water conditions. The analysis model is shown in Figure 3:

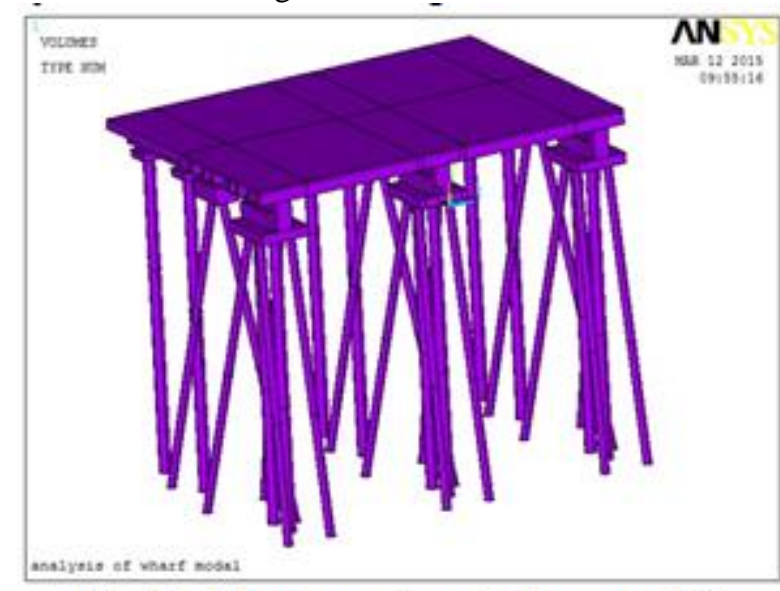

(a) Model diagram in waterless conditions

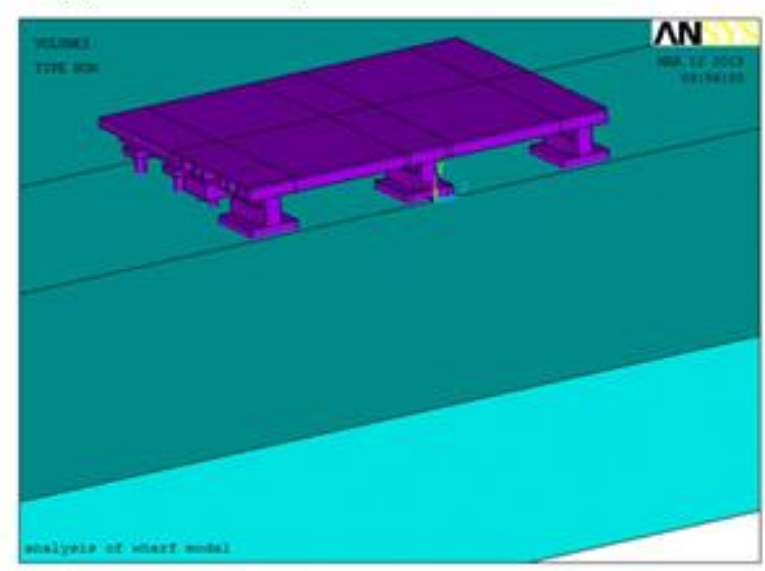

(b) Model diagram in water conditions

Fig 3 The model of wharf modal analysis

\section{Boundary conditions}

In the modal analysis, the interaction between the soil and the pile foundation is generally treated by the equivalent pile method and the bent point method. In this paper, the method of bending and embedding is adopted. According to the "Code for Pile Foundations of Port Engineering" ${ }^{[9]}$, the depth 
of the embedded point of the pier is determined to be $t=4.2 \mathrm{~m}$, and the embedded point is set as consolidation.

\section{MODAL ANALYSIS RESULTS AND ANALYSIS}

1. Wharf natural frequency analysis

Using the ANSYS software, the first ten natural frequencies of the dock with water and water are obtained, as shown in Table 2:

Table 2 The modal analysis results of wharf

\begin{tabular}{lll}
\hline \multirow{2}{*}{ Modal order } & \multicolumn{2}{l}{ Natural frequency $(\mathrm{Hz})$} \\
\cline { 2 - 3 } & Waterless & Water \\
\hline The first order & 1.3676 & 1.3659 \\
The second order & 2.0185 & 2.0155 \\
The third order & 2.0946 & 2.0905 \\
The fourth order & 6.0829 & 6.0294 \\
The fifth order & 6.2683 & 6.2439 \\
The sixth order & 8.6398 & 8.5093 \\
The seventh order & 8.6582 & 8.5223 \\
The eighth order & 10.105 & 9.805 \\
The ninth order & 10.145 & 9.862 \\
The tenth order & 10.533 & 10.235 \\
\hline
\end{tabular}

2. Analysis of natural frequency distribution characteristics The modal distribution of the high-pile wharf structure under waterless conditions is analyzed. Figure 4 shows the natural frequency distribution curves of the wharf structure under waterless conditions.

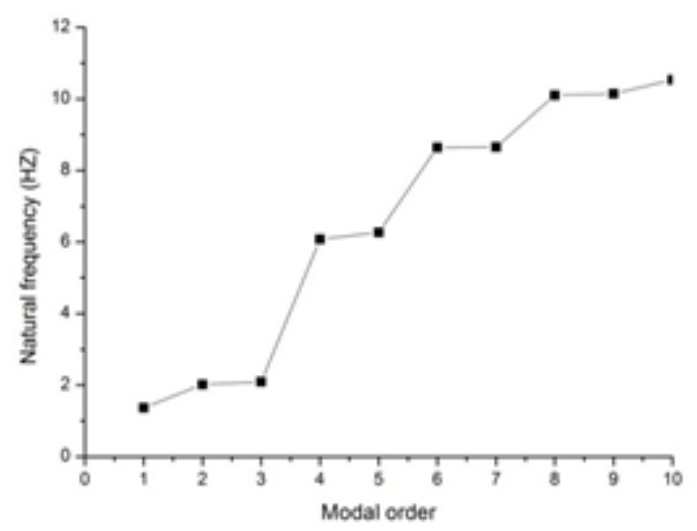

Fig 4 The inherent frequency distribution curve under the anhydrous condition

It can be obtained from Fig. 4 that the natural frequencies of the various structures in the waterless condition are distributed in stages with the increase of the modal order. The first three frequencies of the structure are between 1.3-2.1 Hz, and the change between them is not very large, indicating that the pier structure stiffness is relatively uniform. The natural frequency increases significantly in the fourth-order and fifth-order modes and increases to above $6 \mathrm{~Hz}$. At this time, the difference between the fourth and fifth-order frequencies is small, and the modal frequency distribution tends to be stable. With the gradual increase of the modal order, the natural frequency of the wharf structure also increases. The analysis results show that in the first ten-order modal distribution of the high-pile wharf structure, there are four intervals in which the natural frequency distribution tends to be stable. The four intervals are the first to third order frequency, the fourth to fifth order frequency, and the sixth to seventh order. The frequency and the eight to tenth order frequency, and then the natural frequency of the structure increases as the modal order increases.

3. Analysis of the influence of water on the vibration frequency of the wharf

The modal distribution of the high-pile wharf structure under water and waterless conditions is analyzed. Figure 5 shows the natural frequency distribution curves of the wharf structure under water and waterless conditions.

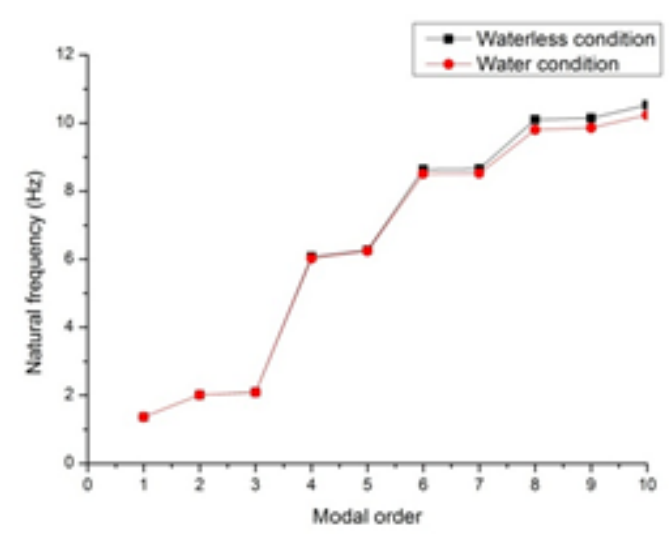

Fig 5 The inherent frequency distribution curve under the water and anhydrous conditions

It can be seen from Fig. 5 that the natural frequency of the wharf is reduced by the presence of water, because the influence of water on the inherent characteristics of the wharf in modal analysis is manifested in the fact that water acts on the structure in the form of additional mass and damping, resulting in the natural frequency of the structure reduce. Analysis of five modal frequency, no water condition and size of the water frequency condition, when the order frequency than five water when waterless decreased $0.12 \%, 0.15 \%$, $0.20 \%, 0.88 \%, 0.39 \%$. In the higher-order mode, because of the increase of the natural frequency of the structure, the influence of water on the structural mode also increases, comparing the natural frequencies of the sixth to tenth order in the waterless and water conditions, frequency of the latter is $1.51 \%$ lower than that of the former, $1.57 \%, 2.97 \%, 2.79 \%$, and $2.83 \%$ respectively. It can be seen from the above analysis that water has a certain influence on the natural frequency of the structure, and as the natural frequency of the structure increases, the influence of water on the natural frequency of the structure also increases.

4. Analysis of the vibration mode of the wharf structure

The structural mode is the structural form that the structure exhibits when it vibrates. Any type of structural mode will have a natural frequency corresponding to it. In this paper, the results of solving the vibration mode of the wharf on water and waterless conditions are analyzed. The existence of water will have a very small effect on the vibration mode of the structure, and there is little difference between the modes of each order under the condition of water and waterless. This is because the structural stiffness determines the structural vibration mode. The structure takes the first vibration in places with low stiffness, and water has no effect on the structural stiffness. Therefore, the mode shape of the structure will not change under the condition of water and waterless. In this paper, the shape of the structure in the state of no water is 
selected. After calculation, the first ten modes of the structure shown in Fig. 6 are obtained, as shown below: (The dotted line is the original model boundary)

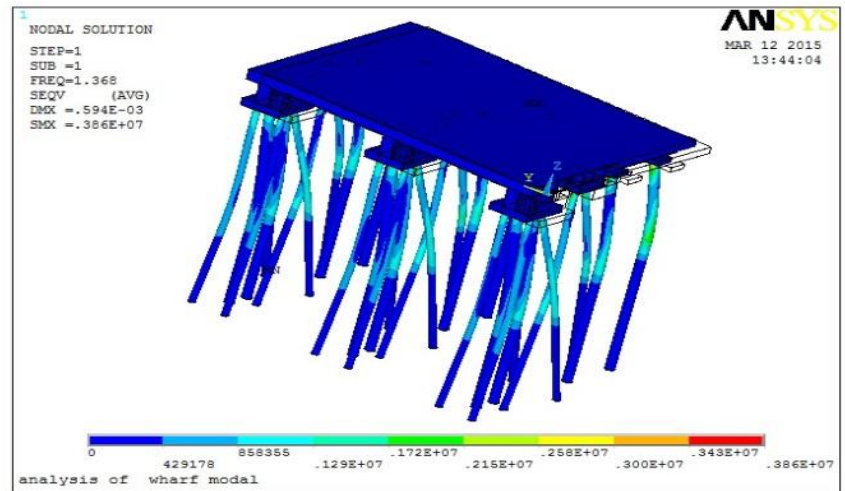

(a)The first order

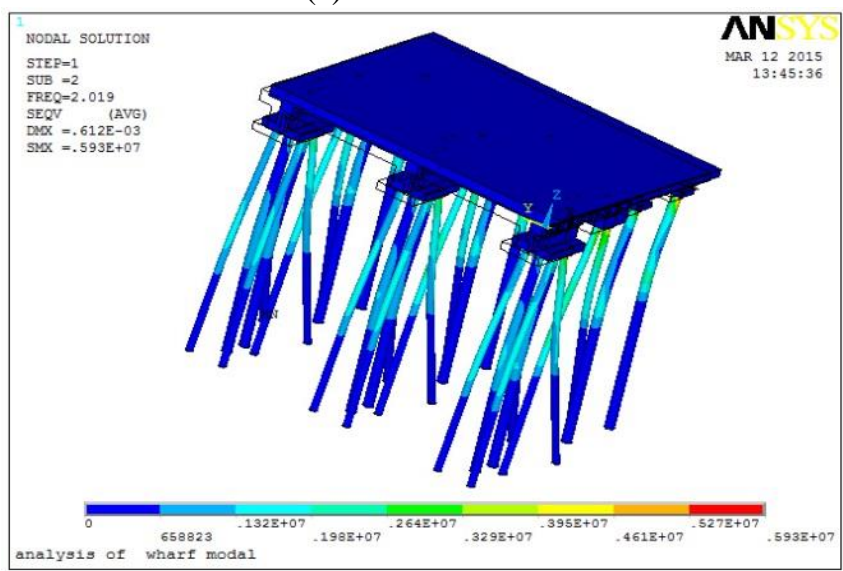

(b)The second order

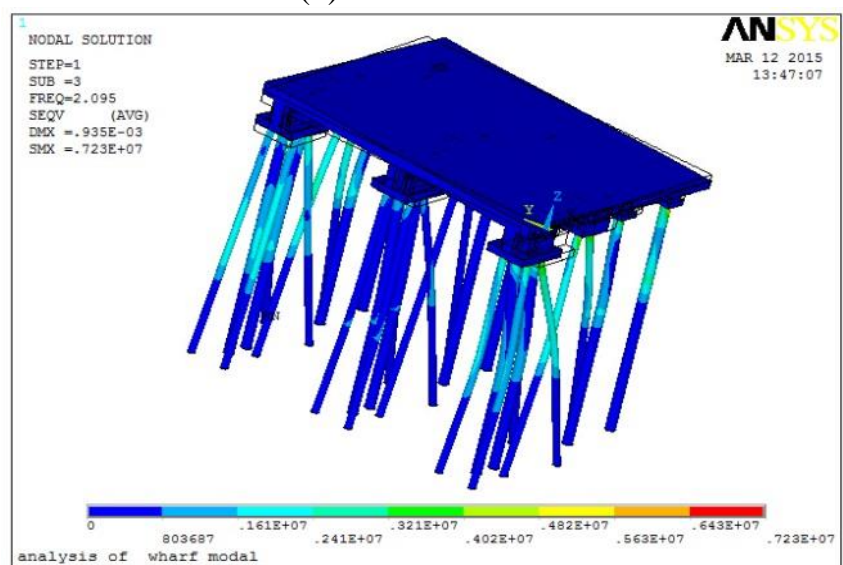

(c)The third order

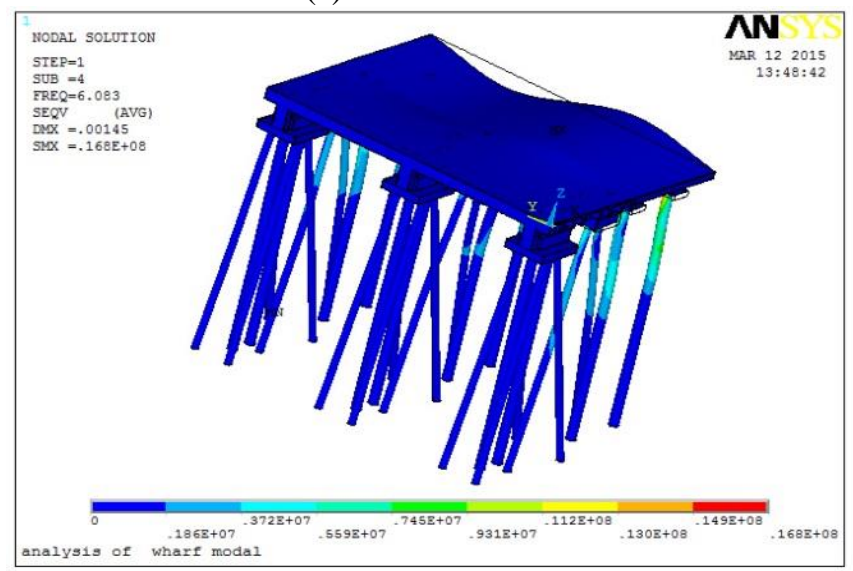

(d)The fourth order

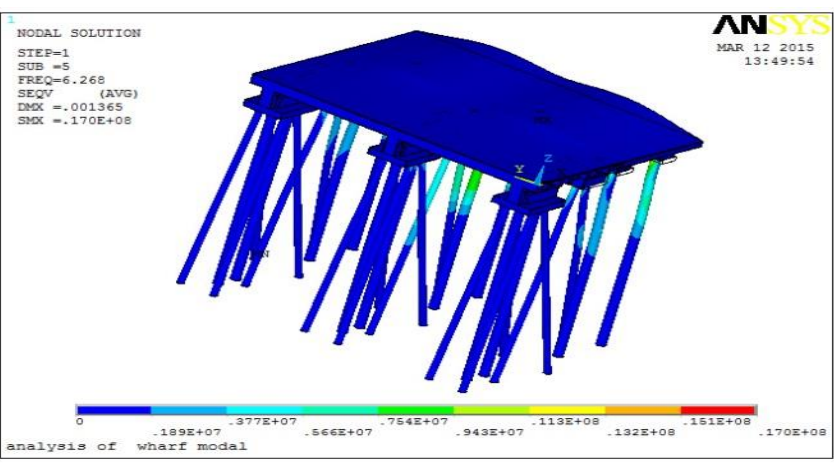

(e)The fifth order

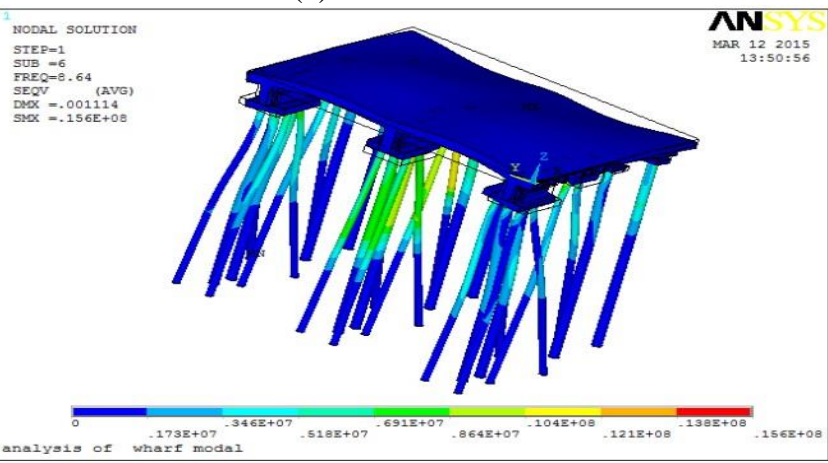

(f)The sixth order

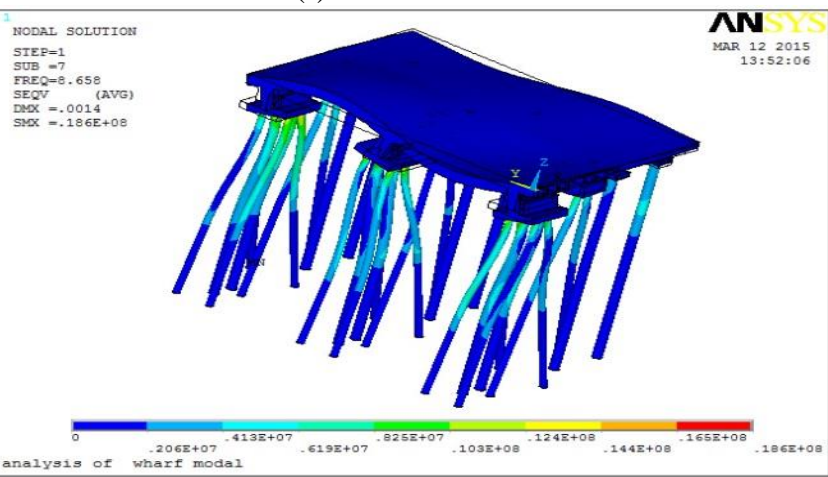

(g)The seventh order

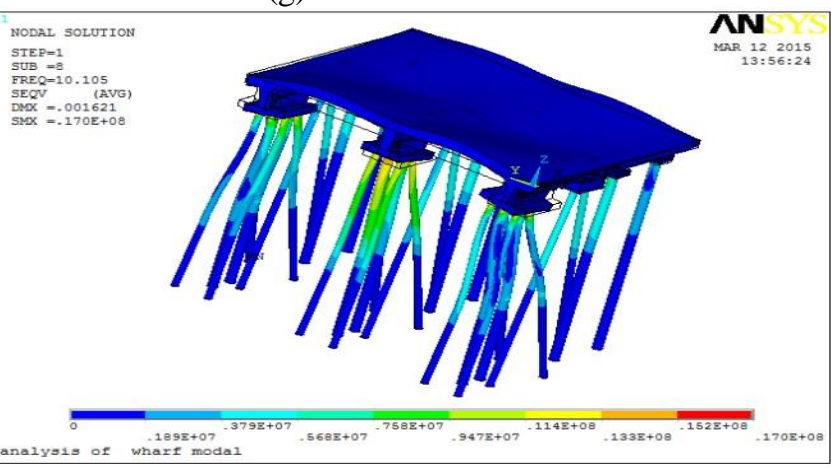

(h)The eighth order

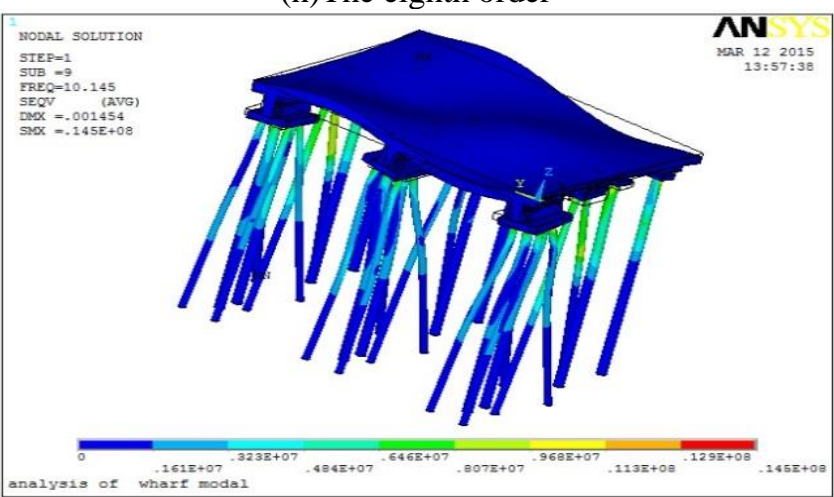

(i)The ninth order 


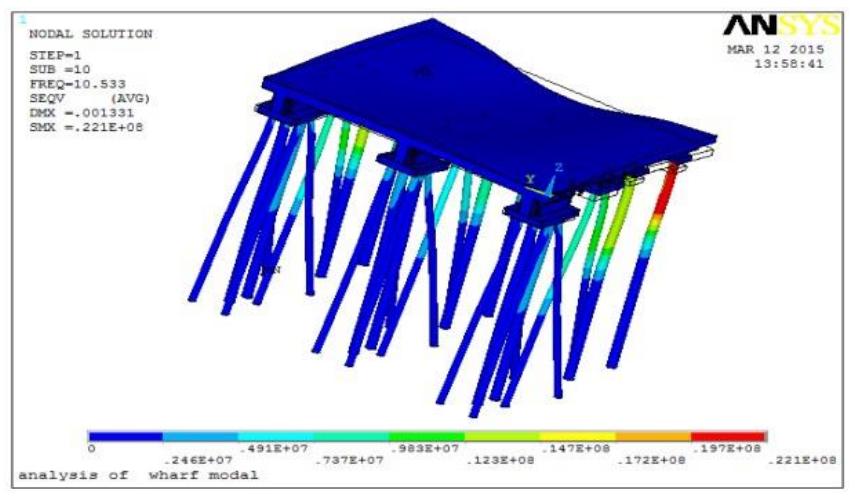

(j)The tenth order

Fig6 The modal vibration mode of high-piled wharf

Since the vibration mode shape of structure is directly related to the severity of vibration damage, so the first ten modes wharf structures morphology analysis, modal morphological characteristics obtained are shown in Table 3:

Table 3 The series modal modes

\begin{tabular}{ll}
\hline $\begin{array}{l}\text { Modal } \\
\text { order }\end{array}$ & Modal characteristics \\
1 & $\begin{array}{l}\text { The structure as a whole vibrates in the } \\
\text { longitudinal direction, and the amplitude } \\
\text { decreases from top to bottom. } \\
\text { The structure is laterally vibrating as a whole, } \\
\text { and the amplitude is decreased from top to } \\
\text { bottom. } \\
\text { The structure twists vibration clockwise in the } \\
\text { horizontal plane, and the torsion angle } \\
\text { decreases from top to bottom. } \\
\text { The structure of the rear platform with wavy } \\
\text { vibration } \\
\text { The rear of the wharf structure is symmetrically } \\
\text { wavy } \\
\text { The rear frame of the structure is symmetrical } \\
\text { wave-shaped vibration downward, and the front } \\
\text { platform is symmetrical wave-shaped upward. } \\
\text { The front and rear caps of the wharf structure } \\
\text { are oscillating in opposite directions } \\
\text { Symmetrical torsional vibration of the structure } \\
9\end{array} \quad \begin{array}{l}\text { along the longitudinal direction } \\
\text { Wharf irregular wavy vibration } \\
\text { The wharf structure is irregularly vibrating in } \\
\text { the longitudinal direction }\end{array}$ \\
\end{tabular}

It can be seen from the above table that when the wharf structure is self-oscillated, its mode shape changes from simple mode to complex mode. The first three orders of the structure have low natural frequencies and are easy to be excited first to cause structural resonance. Therefore, during the work of the high pile wharf, try to avoid vibration sources similar to the first three frequencies

\section{THE CONCLUSION}

This paper first introduces the basic theory of flow-solid coupling modal analysis of wharf structure, then uses ANSYS software to study the dynamic characteristics of the wharf under water and waterless conditions, and discusses the natural frequency and the vibration mode of the wharf structure. Finally leads to the following conclusions:

(1) In the first ten-order modal distribution of the high-pile wharf structure, there are four intervals in which the natural frequency distribution tends to be stable. The four intervals are the first to third order frequency, the fourth to fifth order frequency, and the sixth to seventh order. Frequency and eight to tenth order frequency.

(2) The first three orders of frequency are relatively low, which is easy to be excited and cause resonance. Therefore, effective measures should be taken to prevent the occurrence of vibration sources close to the first three orders of frequency when the wharf is on working. Then the vibration mode of the structure becomes more complicated and the frequency is also will increase with it.

(3) The natural frequency of the wharf is reduced by the presence of water because the effect of water on the intrinsic characteristics of the wharf in modal analysis is manifested in the fact that water acts on the structure in the form of additional mass and damping, resulting in a decrease in the natural frequency of the structure. And with the increase of the structural vibration frequency, the influence of water on the vibration frequency of the structure also increases.

\section{REFERENCES}

[1] Han Rian. Port hydraulic structure [M]. Second edition. Beijing: China Communications Press, 2008.109.

[2] Zhou Shiliang, Wu Feiqiao, Wang Quan, Li Fenghua. Structural modal analysis of overhead pier type bulk cargo terminal in the Three Gorges Reservoir area [J]. Port Engineering Technology, 2010, 47 (3): 25-27.

[3] Xu Weij, Lei Guogang, Li Zeyi. Cause analysis and treatment countermeasures for sloshing of high-pile beam-slab pier [J]. Water Transport Engineering, 2011, (2): 58-62.

[4] Liu Wei, Gao Weicheng, Yu Guangbin. ANSYS 12.0 revered book [M]. Beijing: Publishing House of Electronics Industry, 2010.07.

[5] Fu Zhifang, Hua Hongxing. Theory and Application of Modal Analysis [M]. Shanghai: Shanghai Jiaotong University Press, 2000.

[6] Yang Kang,Han Tao.Application of ANSYS in Modal Analysis[J].Journal of Jiamusi University(Natural Science Edition),2005 (1): 85-88.

[7] Hua Xiaomin, Zhou Xiaochun, Li Zengguang. Design of 2\# 5\# berth wharf structure reinforcement and reconstruction project in Zhengang Port Dagang Port Area [J]. Water Transport Engineering, 2011, 10 (10): 71-75.

[8] Lin Jida. Research on dynamic response of bottom beam full straight pile wharf structure [D]. Changsha: Master's Thesis of Changsha University of Science and Technology, 2012.

[9] JTS 167-4-2012 Port Engineering Pile Foundation Specification [S]. Beijing: China Communications Press, 2012.

Wang Hong (1960-),male, professor, The research direction is port channel and marine structure engineering.

Feng Sen(1994-),male, master student.

Guo Zhichao(1995-),male, master student 